\title{
Euphol arrests breast cancer cells at the G1 phase through the modulation of cyclin D1, p21 and p27 expression
}

\author{
LIN WANG ${ }^{1,2,3}$, GUIYING WANG ${ }^{2,3}$, DANDAN YANG ${ }^{2,3}$, XUDONG GUO $^{2,3}$, \\ YANXIN XU ${ }^{2,3}$, BO FENG $^{1}$ and JIUHONG KANG ${ }^{2,3}$ \\ ${ }^{1}$ Department of Endocrinology, East Hospital, Tongji University School of Medicine; \\ ${ }^{2}$ Clinical and Translational Research Center of Shanghai First Maternity and Infant Health Hospital; \\ ${ }^{3}$ Shanghai Key Laboratory of Signaling and Disease Research, School of Life Science and Technology, Tongji University, \\ Yangpu, Shanghai 200092, P.R. China
}

Received February 21, 2013; Accepted August 12, 2013

DOI: $10.3892 / \mathrm{mmr} .2013 .1650$

\begin{abstract}
Euphorbia tirucalli is a long-established treatment for a wide variety of cancers. However, the mechanism of its anticancer effect is yet to be elucidated. In the present study, we examined the anticancer effect of euphol, a tetracyclic triterpene alcohol isolated from the sap of Euphorbia tirucalli, in T47D human breast cancer cells. Following the treatment of cells with different doses of euphol for 24,48 and $72 \mathrm{~h}$, the cell proliferation, cell cycle, and mRNA and protein levels of cell cycle regulatory molecules were analyzed, respectively. Treatment of the cells with euphol resulted in decreased cell viability, which was accompanied by an accumulation of cells in the G1 phase. Further studies demonstrated that euphol treatment downregulated cyclin D1 expression and the hypophosphorylation of $\mathrm{Rb}$. Furthermore, this effect was correlated with the downregulation of cyclin-dependent kinase 2 (CDK2) expression and the upregulation of the CDK inhibitors p21 and p27. Reduced expression levels of cyclin A and B1 were also observed, corresponding to the decreased distribution of cells in the $\mathrm{S}$ and $\mathrm{G} 2 / \mathrm{M}$ phases, respectively. These findings indicated that euphol is an active agent in Euphorbia tirucalli that exerts anticancer activity by arresting the cell cycle of cancer cells.
\end{abstract}

Correspondence to: Dr Bo Feng, Department of Endocrinology, East Hospital, Tongji University School of Medicine, 1239 Siping Road, Shanghai 200092, P.R. China

E-mail: fengbo@medmail.com.cn

Dr Jiuhong Kang, Shanghai Key Laboratory of Signaling and Disease Research, School of Life Science and Technology, Tongji University, 1239 Siping Road, Shanghai 200092, P.R. China

E-mail: jhkang@tongji.edu.cn

Key words: euphol, breast cancer, G1 arrest, cyclin D1, p21, p27

\section{Introduction}

Breast cancer is one of the most common types of cancer with $>1,300,000$ cases and 450,000 mortalities annually worldwide (1). Although fatalities due to breast cancer are decreasing, breast cancer remains the second leading cause of cancer-related mortality among females $(2,3)$. Regardless of surgical removal of the primary tumor, relapse may occur within a few months to $>40$ years following the presentation of the initial symptoms, and $\geq 15 \%$ of all patients ultimately develop an incurable form of the disease (3). This highlights the requirement for therapies that are able to treat the advanced stages of the disease. Traditional cytotoxic therapy kills neoplastic cells by multiple mechanisms, which also effect normal healthy cells. The non-specificity of these agents produces undesirable side effects, including short term (myelosuppression) and long term (cardiomyopathy and acute leukemia) toxicities (4).

Improvement in the understanding of the molecular mechanisms involved in cancer has led to the identification of novel targets and the development of specific therapies, which are referred to as targeted therapies. Targeted therapies have a high specificity for the molecules involved in the key molecular events responsible for the cancer phenotype (5). Among which, the cell cycle is a promising target involved in cancer growth, as a key characteristic of human breast cancer and other types of cancer is enhanced and deregulated cell cycle activity leading to unrestricted cell growth $(6,7)$.

Medicinal plants have been used worldwide and have been demonstrated to be a source of effective anticancer agents (8). Euphorbia tirucalli, belonging to the family Euphorbiaceae, is a subtropical and tropical ornamental plant. It has a long history of traditional use as a remedy for a variety of conditions, including rheumatism, neuralgia, asthma, catarrh, earache, sarcoma and cancer (9-11). The tetracyclic triterpene alcohol, euphol, is the main constituent in the sap of Euphorbia tirucalli and the biological profiles have evoked investigation to elucidate its potential properties.

Previous studies have demonstrated that euphol exerts antiviral effects by inhibiting reverse transcriptase in purified human immunodeficiency virus type 1 (12) and inhibiting 
the Epstein-Barr virus early antigen activation induced by the tumor promoter 12-O-tetradecanoylphorbol-13-acetate (TPA) (13). The anti-inflammatory effects of euphol have been demonstrated to be associated with the inhibition of the activation of nuclear factor- $\kappa \mathrm{B}$ (14), downregulation of tumor necrosis factor- $\alpha$ and cyclooxygenase-2 (15), inhibition of the $\mathrm{T}$ cell-mediated immune response (15), and the reduction of protein kinase C/extracellular signal-regulated protein kinase signaling activation (16). In addition to the antiviral and anti-inflammatory effects, the antitumor effects of euphol have also been observed. Topical application of euphol was demonstrated to suppress tumor promotion by TPA in mouse skin initiated with 7,12-dimethylbenz(a)anthracene (17). However, the underlying mechanisms involved in the antitumor effect remain to be elucidated.

In the present study, euphol was observed to inhibit the expression of cyclin D1, cyclin A, cyclin B1 and cyclin-dependent kinase 2 (CDK2), decrease the phosphorylation of retinoblastoma $(\mathrm{Rb})$, induce the expression of cyclin-dependent kinase inhibitors (CKI) p21 and p27, and lead to the G1 arrest and proliferation inhibition of T47D cells. These data provide an insight into the anticancer effects of euphol in breast cancer cells.

\section{Materials and methods}

Drugs and antibodies. Euphol was provided by Dr HB Wang (School of Life Science and Technology, Tongji University, Shanghai, China) and was stored at $4^{\circ} \mathrm{C}$. Stock solutions of euphol were prepared at a concentration of $100 \mathrm{mM}$ in dimethyl sulfoxide (DMSO). Further dilutions were immediately prepared prior to each experiment and not exceeding $0.3 \%$ DMSO (v/v) in the culture media. Control cells were treated with the same quantity of DMSO as used in the corresponding treatment. The following primary antibodies were used for western blot analysis: Human cyclin A, CDK2, Rb, phosphorylated (p)-Rb (Bioworld Technology Co., Ltd., St. Louis Park, MN, USA); cyclin B1, cyclin D1, cyclin E, p27 (Santa Cruz Biotechnology, Inc., Santa Cruz, CA, USA); p21 (Abcam, Cambridge, MA, USA) and glyceraldehyde 3-phosphate dehydrogenase (Santa Cruz Biotechnology, Inc.).

Cell lines and culture. The T47D breast cancer cell line was purchased from Cell Bank Type Culture Collection of Chinese Academy of Sciences (Shanghai, China). Cells were cultured in RPMI-1640 culture medium (Thermo Fisher Scientific, Shanghai, China) supplemented with $10 \%$ fetal bovine serum (Biochrom, AG, Berlin, Germany), $100 \mathrm{U} / \mathrm{ml}$ penicillin (Gibco-BRL, Grand Island, NY, USA) and $100 \mu \mathrm{g} / \mathrm{ml}$ streptomycin (Gibco-BRL) in an incubator at $37^{\circ} \mathrm{C}$ in a $5 \% \mathrm{CO}_{2}$ humidified atmosphere.

Cell proliferation assay. Cell proliferation was determined by a methyl-thiazol tetrazolium (MTT) assay. Cells were seeded at a density of $5 \times 10^{3}$ cells/well in 96-well plates and treated with euphol at the indicated concentrations. Following 24, 48 and $72 \mathrm{~h}$ incubation, $20 \mu \mathrm{l}$ sterile MTT $(5 \mathrm{mg} / \mathrm{ml}$, Sigma-Aldrich, St. Louis, MO, USA) were added to each well. Subsequent to incubation at $37^{\circ} \mathrm{C}$ for $4 \mathrm{~h}, 150 \mu \mathrm{l}$ DMSO was added to solubilize the MTT-formazan product and mixed thoroughly. The spectrometric absorbance at $490 \mathrm{~nm}$ was measured with an enzyme immunoassay analyzer (FlexStation 3TM; Molecular Devices, Sunnyvale, CA, USA). Percentage cell survival was calculated using the optical density as follows: \% cell survival $=$ (absorbance of treated cells $/$ absorbance of cells with vehicle solvent) $\mathrm{x} 100$. The half inhibitory concentration (IC50) values, defined as the concentration of drug that caused $50 \%$ inhibition of absorbance compared with the control cells, were calculated from the dose-response curve obtained by plotting percentage of cell survival versus the concentration of euphol.

Flow cytometry analysis for cell cycle distribution. To determine the effect of euphol on the cell cycle, fluorescence-activated cell sorting (FACS) analysis was conducted. Cells $\left(3.5 \times 10^{5}, 4.5 \times 10^{5}\right.$ and $6 \times 10^{5} /$ well $)$ were seeded in 6 -well plates and treated with the indicated euphol concentrations for 24, 48 and 72 h, respectively. Attached cells were harvested at the indicated time points, washed in phosphate-buffered saline, fixed in ice-cold ethanol $(75 \%)$ and stored at $-20^{\circ} \mathrm{C}$. For analysis, fixed cells were stained with propidium iodide $(0.05 \mathrm{mg} / \mathrm{ml})$ containing RNase $(0.2 \mathrm{mg} / \mathrm{ml})$ for $1 \mathrm{~h}$ at room temperature in the dark. FACS analysis was performed using the Guava EasyCyte ${ }^{\mathrm{TM}}$ 8HT (Millipore, Billerica, MA, USA) and data were analyzed using the FlowJo software program (Treestar Inc., Ashland, OR, USA) . Percentages of cell populations distributed in the various phases of the cell cycle (sub-G1, G0/G1, S and G2/M) were calculated.

$q P C R$. Total RNA was isolated using the RNAiso Plus (Takara Bio Inc., Shiga, Japan), and the first strand of cDNA synthesis was performed using the TianScript RT kit (Tiangen Biotech, Co., Ltd., Beijing, China) and the Oligo(dT) ${ }_{15}$ primer from $2 \mu \mathrm{g}$ total RNA, according to the manufacturer's instructions. The mRNA levels were observed by quantitative PCR with SYBR ${ }^{\circledR}$ Premix Ex Taq ${ }^{\mathrm{TM}}$ II (Takara Biotechnology Co., Ltd., Dalian, China) and primers, as listed in Table I, using the Mx3000P qPCR System (Agilent Technologies, Inc., Santa Clara, CA, USA). The relative expression level of each candidate gene was calculated by the $2^{-\Delta \Delta C t}$ method (18), using $\beta$-actin as the internal normalized control with the same calibrator. Each experiment was performed independently and in triplicate.

Western blot analysis. Cells were homogenized with radio immunoprecipitation assay (RIPA) lysis buffer (Beyotime Biotech, Jiangsu, China), followed by sonication on Sonicators (Qsonica, Newton, CT, USA) at a frequency of $20 \mathrm{kHz}$ and centrifugation at $13,800 \mathrm{x}$ g for $10 \mathrm{~min}$ at $4^{\circ} \mathrm{C}$. Subsequent to this the supernatant was harvested and the protein concentration measured using the Pierce BCA protein assay reagent (Pierce, Rockford, IL, USA). Following this, $20 \mu \mathrm{g}$ protein was separated on $12 \%$ sodium dodecyl sulfate-polyacrylamide gel electrophoresis and electrotransferred to a nitrocellulose membrane (Whatman International Ltd., Germany). The membrane was blocked by incubation in 3\% bovine serum albumin, fraction V (Life Sciences, Carlsbad, CA, USA) in TBST buffer (10 mM Tris- $\mathrm{HCl}, \mathrm{pH} 7.6,150 \mathrm{mM} \mathrm{NaCl}$ and $0.1 \%$ Tween 20) and incubated with the primary antibodies at $4^{\circ} \mathrm{C}$ overnight. The blot was washed with TBST buffer, incubated with the corresponding horseradish peroxidase-conjugated 
Table I. Primer sequences of target genes for qPCR analysis.

\begin{tabular}{lll}
\hline Gene & \multicolumn{1}{c}{ Forward primer } & \multicolumn{1}{c}{ Reverse primer } \\
\hline cyclin A2 & AGACCTACCTCAAAGCACCACAG & GGTTGAGGAGAGAAACACCATGA \\
cyclin B1 & TGGATAATGGTGAATGGACACCAA & GCCAGGTGCTGCATAACTGGA \\
cyclin E1 & CTGTGCATCTACACCGACAACTC & AGGTTCCACTTGAGCTTGTTCAC \\
CDK1 & GCCAGCCTTGGGACAATAATG & CTTGCACGTTGAGTTTGGGT \\
CDK2 & TACATTTCCCAAATGGAAACCAG & AATTCGTTTGGCTGGATCATAGA \\
CDC25 & TGAAGATGGACGGAGCTTGTTAT & CTTGGTCACATCCTGGAAGAAAG \\
p21 & ACAGCTCCTCTCGTCATGAGAAC & GGTCTCTTCAACACTGACCGAGT \\
p27 & CGATGGAACTTCGACTTTGTCA & GCACAAGGGTACAAGACAGTG \\
-actin & GGTTAGCGGAGCAATGCG & TCCACAGAACCGGCATTTG \\
\hline
\end{tabular}

CDK, cyclin dependent kinase.

A

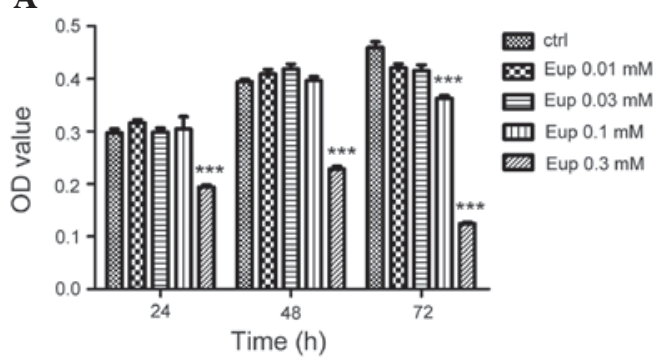

B

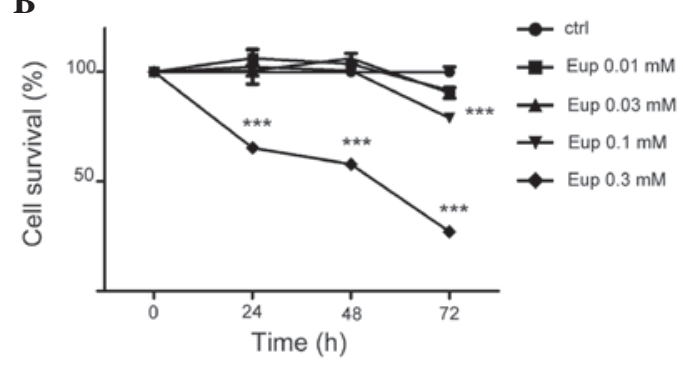

C

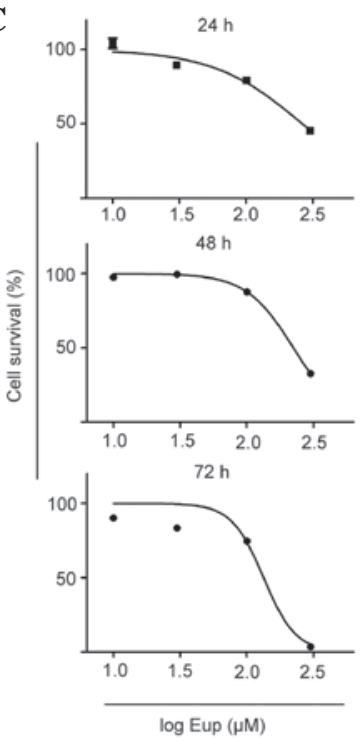

Figure 1. Euphol inhibited the proliferation of T47D breast cancer cells. T47D cells were treated with euphol at the indicated concentrations $(0.01,0.03,0.1$ and $0.3 \mathrm{mM}$ ) for the indicated times (24, 48 and $72 \mathrm{~h}$ ). (A) Cell viability was assessed by a methylthiazol tetrazolium assay (see Materials and methods). Columns, mean absorbance at $490 \mathrm{~nm}$ of quintuplicate readings from a representative experiment; bars, \pm standard error. (B) Percentage cell survival was calculated as: \% cell survival $=($ absorbance of treated cells/absorbance of cells with vehicle solvent) $\mathrm{x} 100 .(\mathrm{C})$ The dose-response curve was obtained by plotting the percentage of cell survival versus the log concentration of euphol used. Points, mean percentage of cell survival based on quintuplicate assays, bars, \pm SE. ${ }^{* * *} \mathrm{P}<0.001$ vs. the control group. OD, optical density; Eup, euphol; ctrl, control; OD, optical density.

secondary antibody for $1 \mathrm{~h}$ at room temperature and visualized by ImageQuant LAS 4000mini (GE Healthcare Life Sciences, Piscataway, NJ, USA).

Statistical analysis. Data were analyzed by a two-tailed Student's t-test. Final values are presented as the mean \pm standard error. $\mathrm{P}<0.05$ was considered to indicate a statistically significant difference. $\mathrm{P}<0.05, \mathrm{P}<0.01$ and $\mathrm{P}<0.001$ are denoted as ${ }^{*},{ }^{* *}$ or ${ }^{* * *}$, respectively.

\section{Results}

Euphol inhibits cell proliferation. To evaluate the effect of euphol on breast cancer cell proliferation, the MTT assay was performed in T47D cells, an aggressive triple-positive breast cancer cell line. Briefly, exponentially growing T47D cells were treated with $0.01,0.03,0.1$ and $0.3 \mathrm{mM}$ euphol for 24 , 48 and $72 \mathrm{~h}$. With an increased concentration of euphol, the percentage of viable cells was significantly decreased, particularly following treatment with $0.03 \mathrm{mM}$ euphol (Fig. 1A and B). The IC50 values of euphol treatment for 24, 48 and $72 \mathrm{~h}$ were $0.26,0.22$ and $0.13 \mathrm{mM}$, respectively (Fig. 1C). These data suggested that euphol markedly inhibited breast cancer cell proliferation.

Euphol induces cell cycle arrest. To investigate the functional mechanism of euphol in inhibiting cell growth, the effect of euphol on the regulation of the cell cycle in T47D cells was determined. Cells treated with euphol were stained with PI and analyzed by flow cytometry. Following $24 \mathrm{~h}$ of treatment, 
A

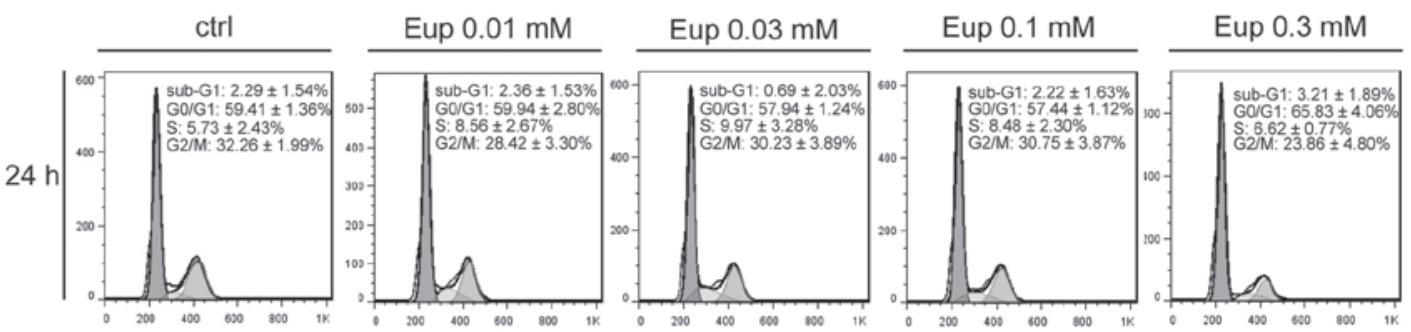

B

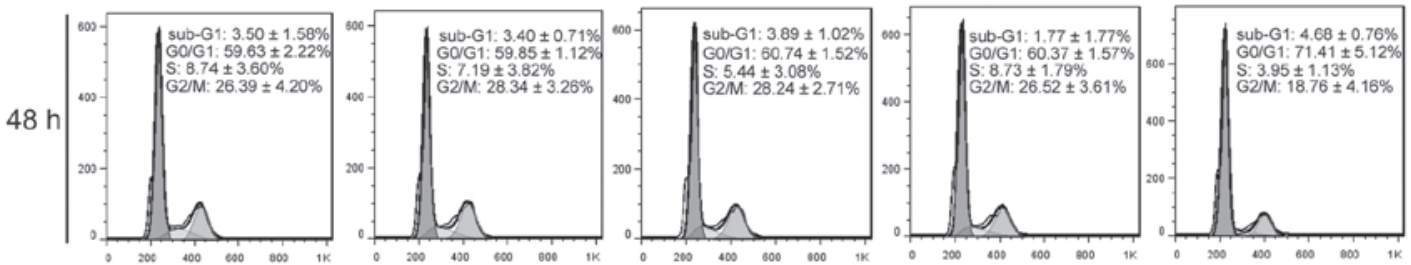

C

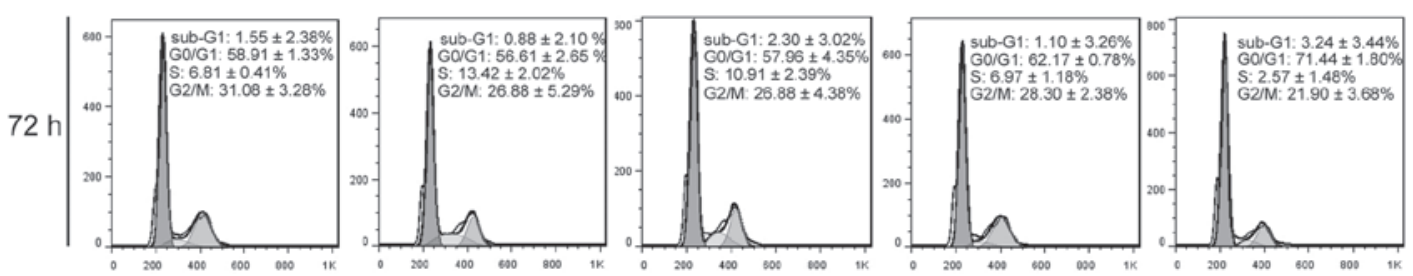

D
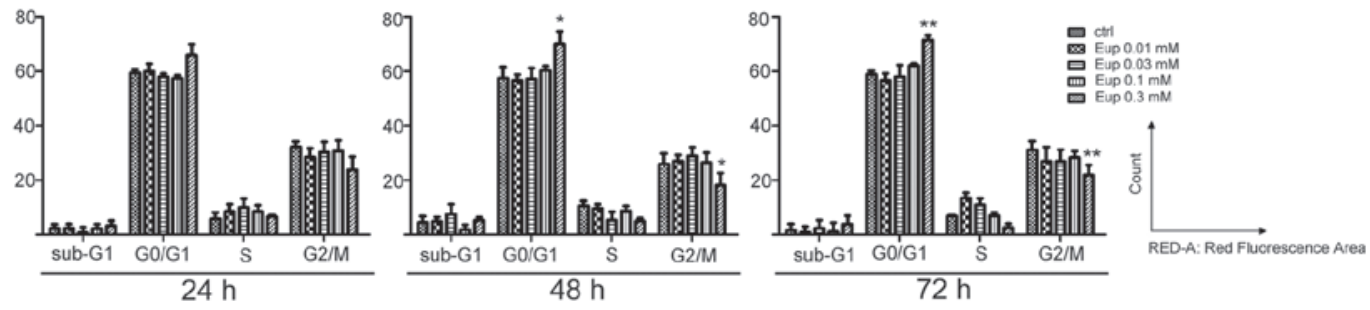

Figure 2. Euphol induced G1 arrest in T47D breast cancer cells. T47D cells were collected, fixed and stained with PI for fluorecscence-activated cell sorting analysis with the indicated concentrations of euphol for (A) $24 \mathrm{~h}$ (B) $48 \mathrm{~h}$ and (C) $72 \mathrm{~h}$. (D) Cell cycle profiles were analyzed by flow cytometry and the percentages of cells distributed in the sub-G1, G0/G1, S and G2/M phases were calculated by the FlowJo program. Columns, mean percentage of cell distributions from three independent experiments; bars, \pm standard error. ${ }^{*} \mathrm{P}<0.05$ and ${ }^{* *} \mathrm{P}<0.01$ vs. the control group. ctrl, control; Eup, euphol.

A

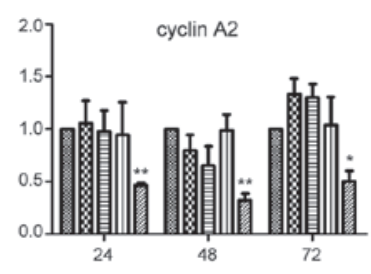

B

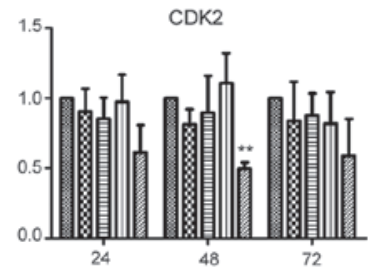

C

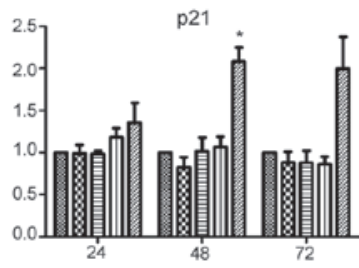

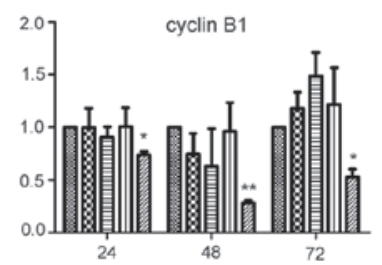
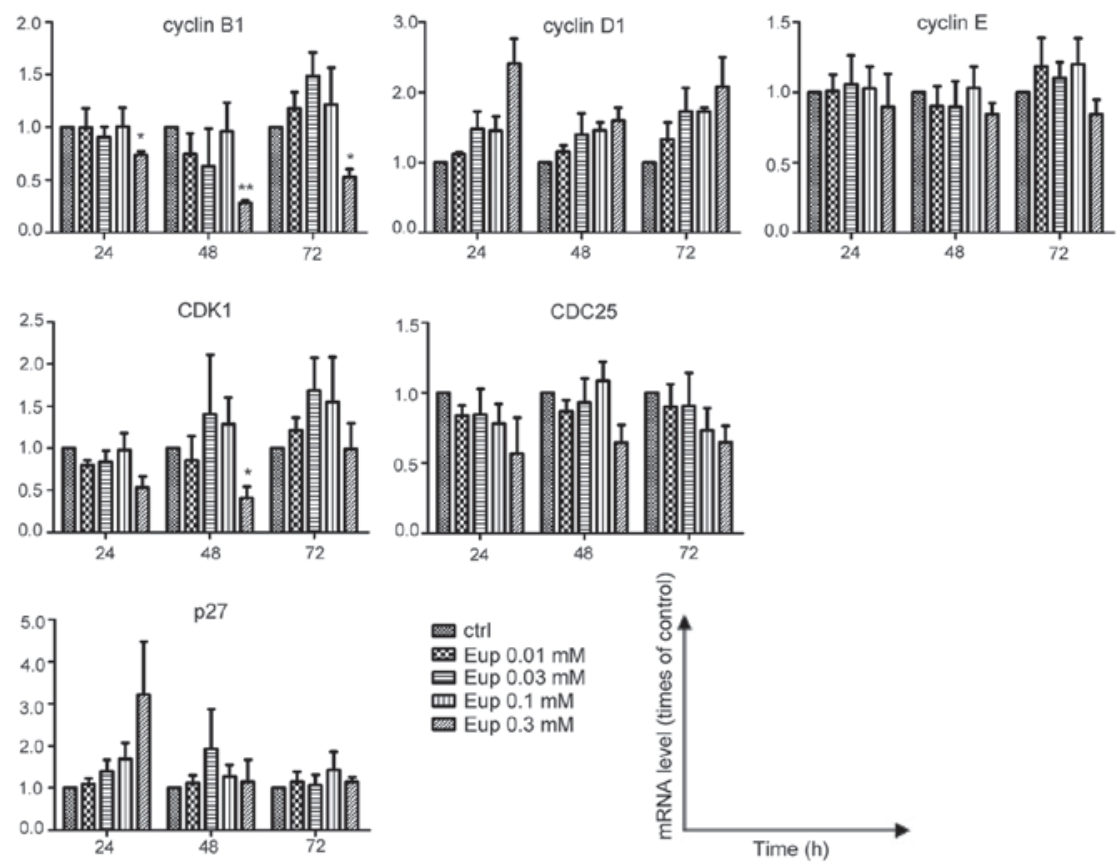

Figure 3. Downregulation of the expression of cell cycle genes in T47D cells. T47D cells were treated with euphol at the indicated concentrations $(0.01,0.03$, 0.1 and $0.3 \mathrm{mM}$ ) for the indicated times $(24,48$, and $72 \mathrm{~h})$. The mRNA levels of (A) cyclins, (B) CDK and (C) CKIs were examined by qPCR. $\beta$-actin was used as an internal normalization control. Columns, mean of triplicate experiments; bars, \pm SE. CDK, cyclin-dependent kinase; CKI, CDK inhibitor; ctrl, control; Eup, euphol. 


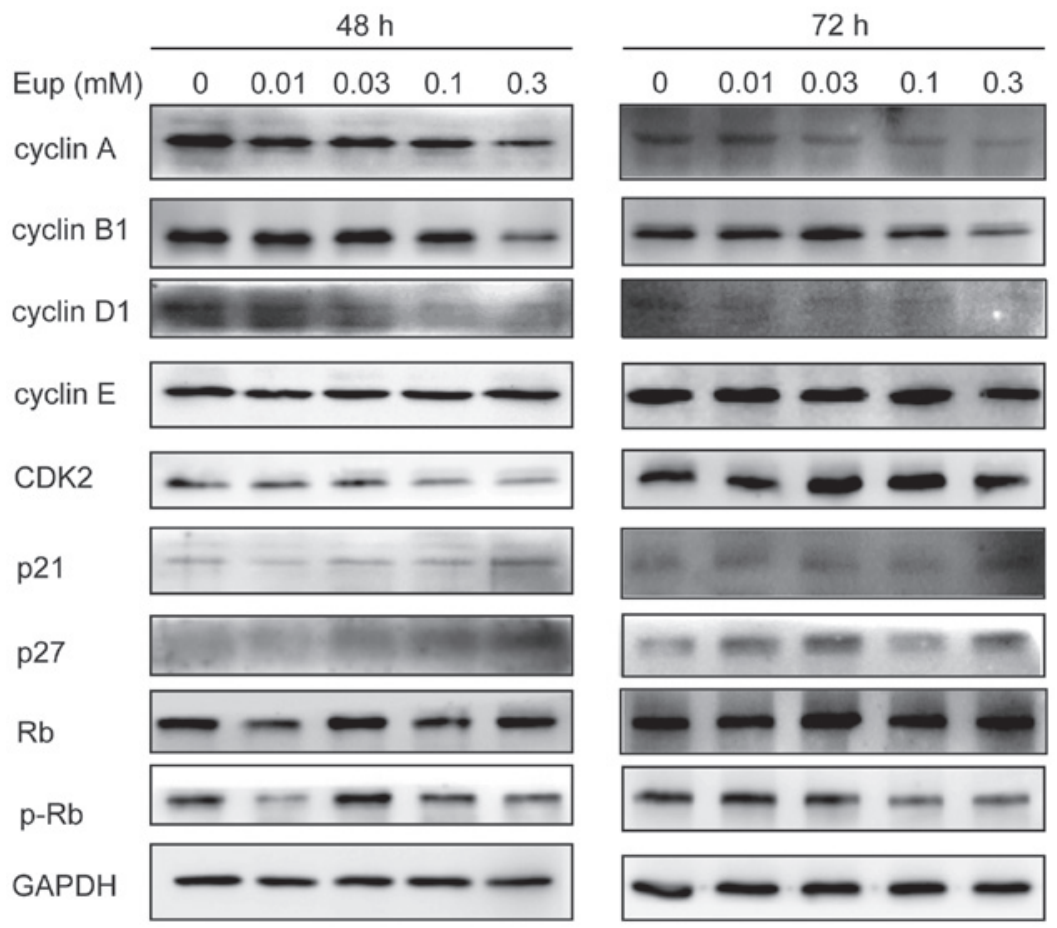

Figure 4. Euphol regulated the expression of cell cycle proteins in T47D cells. Cell lysates were analyzed by western blotting using specific antibodies to cyclin A, B1, D1 and E, as well as to CDK2, p21, p27, Rb and p-Rb protein. Protein loading was normalized based on GAPDH. Eup, euphol; CDK, cyclin-dependent kinase; $\mathrm{p}$-Rb, phosphorylated-Rb protein; GAPDH, glyceraldehyde 3-phosphate dehydrogenase.

stability was observed in all cell cycle subpopulations, with a slight increase in the G0/G1 and a decrease in the $\mathrm{S}$ and G2/M populations treated with $0.3 \mathrm{mM}$ euphol (Fig. 2A and D). Following $48 \mathrm{~h}$ incubation, euphol $(0.3 \mathrm{mM})$ caused a redistribution of the cell cycle resulting in a significant increase of the G0/G1 sub-population from 59.63 to $71.41 \%$, and a concomitant decrease in the G2/M subpopulation from 26.39 to $18.76 \%$ (Fig. 2B and D). At $72 \mathrm{~h}$, a significant increase remained in the G0/G1 population to the detriment of the $\mathrm{S}$ and G2/M subpopulations in $0.3 \mathrm{mM}$ euphol treatment (G0/G1: Control, $58.91 \%$, $0.3 \mathrm{mM}$ euphol, 71.44\%; S: Control, 6.81\%, $0.3 \mathrm{mM}$ euphol, 2.57\%; G2/M: Control, 31.08\%, $0.3 \mathrm{mM}$ euphol, 21.90\%) (Fig. 2C and D). Notably, no significant changes were observed in the sub-G1 subpopulation at any indicated concentration or time point. The level remained low at 3.21, 4.68, and $3.24 \%$ for 24, 48 and $72 \mathrm{~h}$ at $0.3 \mathrm{mM}$ euphol, respectively (Fig. 2A, $2 \mathrm{~B}$ and $2 \mathrm{C}$ ). These results indicated that euphol may inhibit cell proliferation by arresting the cells at the G0/G1 phase and preventing them from entering the $\mathrm{S}$ phase.

Euphol regulates transcription levels of cell cycle-associated genes. To elucidate whether the genes involved in the cell cycle redistribution were induced by euphol, the mRNA levels of cell cycle-associated genes were observed following treatment with euphol. Genes selected for analysis included cyclin A2, B1, D1 and E, cyclin-dependent kinase 1 (CDK1), CDK2, cell division cycle 25 and p21 and p27 (CKIs) The results of the qPCR analysis showed that incubation with euphol (0.3 mM), for 24, 48 and $72 \mathrm{~h}$, significantly downregulated the mRNA levels of cyclin A2 and B1 (Fig. 3A). Furthermore, the mRNA levels of CDK1 and CDK2 were significantly reduced following treatment with euphol
(0.03 mM) for $48 \mathrm{~h}$ (Fig. 3B). The mRNA levels of p21 were also significantly increased following treatment with euphol (0.03 mM) for $48 \mathrm{~h}$ (Fig. 3C).

Euphol regulates expression of cell cycle-associated proteins. To identify the proteins involved in euphol-induced cell cycle arrest, the effect of euphol on the protein levels involved in the cell cycle redistribution were determined. Whole-cell lysates were prepared following treatment with euphol for 48 or $72 \mathrm{~h}$, and the expression levels of cyclin A, B1, D1 and E, as well as CDK2, p21, p27, Rb and p-Rb, were detected by western blot analysis (Fig. 4). Incubation with euphol ( $0.03 \mathrm{mM})$ for $48 \mathrm{~h}$ or $72 \mathrm{~h}$ reduced the expression of cyclin A, B1 and D; however, it increased the expression of p21 and p27. The expression of CDK2 decreased following treatment with euphol $(0.03 \mathrm{mM})$ for $48 \mathrm{~h}$. Furthermore, the level of $\mathrm{p}-\mathrm{Rb}$ was decreased in response to euphol $(0.03 \mathrm{mM})$ compared with that of the control cells despite the fact that the expression level of $\mathrm{Rb}$ was not significantly different between the two. These results suggested that the transcriptional downregulation of certain cyclins and the upregulation of p21 and p27 by euphol may have led to cell cycle arrest, and ultimately resulted in growth inhibition.

\section{Discussion}

Euphol is a tetracyclic triterpene alcohol isolated from the sap of Euphorbia tirucalli. It has been demonstrated to possess a wide variety of biological properties, including antimicrobial, anti-inflammatory and immunosuppressive actions. Yasukawa et al also demonstrated the involvement of euphol in the suppression of skin tumor formation (17). However, 
the exact mechanisms underlying the antitumor effects of euphol have not been fully elucidated. This study investigated the cytostatic effects of euphol on T47D breast cancer cells. According to the results, euphol induced cell cycle arrest at the G0/G1 phase, which resulted in growth inhibition. The arrest may have been mediated by the reduction of cyclin D1 and CDK2, as well as the induction of the CDK inhibitors p21 and $\mathrm{p} 27$, followed by the hypophosphorylation of Rb. Decreased cyclin A and B1 levels correlated with the lower cell counts in the $\mathrm{S}$ and $\mathrm{G} 2 / \mathrm{M}$ phases.

Cyclin D1 is a member of a family of three closely associated D-type cyclins, D1, D2 and D3, which phosphorylate and inactivate $\mathrm{Rb}$ protein and promote progression through the G1-S phase of the cell cycle (19). High levels of cyclin D1 have been detected in numerous breast cancer cell lines through DNA amplification and/or cyclin D1 overexpression (20). This abnormality has been demonstrated to be important in tumorigenesis and to confer a poor prognosis in breast cancer $(21,22)$. In contrast to cyclin D1, cyclin D2 and D3 are not associated with breast tumor formation (4). Activation of the cyclin E-CDK2 complex is another essential requirement for the G1/S transition (23). As observed in this study, euphol exerted proliferation inhibitory effects on T47D cells by leading to their arrest at the G0/G1 phase. When the cell cycle phase distributions are compared with alterations in the cell cycle regulatory molecules, a decrease in Cyclin D1 levels may be attributed as a cause of euphol-induced G0/G1 arrest as well as the inhibition of CDK2. Although the cyclin E level was unchanged, decreased CDK2 may also imply an inhibition of cyclin E and cyclin E-CDK2, as the decrease of cyclins or CDKs constrains the formation of active cyclin-CDK complexes. Consistent with the decreased level of cyclin D1 and CDK2 expression induced by euphol, the $\mathrm{p}-\mathrm{Rb}$ level also decreased, which is probably due to the deficiency of cyclin-CDK complexes in the euphol treated T47D cells. However, the possibility that the two reductions are attributed to the euphol-induced upregulation of CKIs was not excluded.

The predominant CKIs include p21 and p27 of the Cip/Kip family, which inactivate CDK-cyclin complexes $(4,23)$. The increased expression of p21 and p27 by euphol is noteworthy as the development of breast cancer has been associated with a decrease in these CKIs (4). The abundance of p27 is regulated primarily at the post-translational level as demonstrated in the growth factor-mediated reduction in p27 protein levels, primarily through enhanced ubiquitin-mediated degradation (24). Consistent with this study, the transcriptional level of p27 was relatively unchanged based on the qPCR analysis; however, a significant increase was observed in its expression level following euphol treatment. The mechanism of this post-transcriptional regulation of p27 may involve reduced ubiquitination, but this requires further validation. Euphol marginally increased p21 at the transcriptional and post-transcriptional levels compared with that of the untreated control cells. This upregulation may involve a p53-independent pathway, as point mutations in the core DNA binding region and transactivation deficient p53 in the T47D cell line have been demonstrated (25).

Cyclin A is required for the onset of DNA replication in mammalian cells (26) and is rate limiting for the G1/S transition (27). Cylin B is a mitotic cyclin that accumulates at the
G2/M transition and acts synergistically with cyclin A during the initiation of mitosis (28). In correlation with the lower abundance of cells in the S and G2/M subpopulations, mRNA and protein levels of cyclin A and B1 were downregulated by euphol treatment. This is similar to a study demonstrating that decreased levels of cyclin A and B correlated with the decreased levels of cells in the S and G2 phases, and increased levels of cells in the G1 phase, in non-small cell lung cancer (29).

The sub-G1 peak observed by FACS analysis was due to the deficient DNA content in apoptotic cells. Identification of the sub-G1 subpopulation may be used as an index of apoptotic cells in the cell cycle analysis (30), although the lack of changes in the sub-G1 population may also be due to the loss of severely damaged cells during the washing process. In this study, the sub-G1 subpopulation remained at a low level, indicating almost negligible apoptosis in T47D cells treated with euphol. This is concordant with a study demonstrating that T47D cells among 8 human breast cancer cell lines of the National Cancer Institute anticancer drug screen were resistant to apoptosis, and in which no apoptosis was observed with 7-hydroxystaurosporine (UCN-01) and minimal apoptosis was identified with camptothecin. This resistance to apoptosis was considered to be determined by the MDM-2/p53 ratio and to be p53-independent (31). The detected minimal apoptosis induced by euphol in T47D cells may be explained by this mechanism. In addition, the extent to which the MDM2/p53 ratio contributed to apoptosis resistance requires further elucidation.

The current study indicated important features of euphol concerning its capacity to target the cell cycle, thus, euphol may be a potential cancer chemotherapy agent. The underlying mechanism of action involved the reduction of cyclin D1, A and B1 levels, downregulation of CDK2, hypophosphorylation of $\mathrm{Rb}$ and the induction of CKIs p21 and p27. Although this study has demonstrated the euphol-induced regulation of the cell cycle molecules in T47D cells, further investigation regarding combination therapy leading to lower doses of therapeutic agents and observations of other cancer cell lines are required.

\section{Acknowledgements}

This study was supported by funding from the Ministry of Science and Technology (grant nos. 2011CB965100, 2011CBA01100, 2011DFA30480, 2010CB944900, 2010CB945000 and 2012CB966603); the National Natural Science Foundation of China (grant nos. 91219305, 31101061, 31210103905, 31071306, 31000378, 31171432 and 81170499); the Science and Technology Commission of Shanghai Municipality (grant nos. 11ZR1438500 and 11XD1405300); and the Ministry of Education (grant nos. IRT1168 and 20110072110039). The study was also supported by the Chen Guang project supported by Shanghai Municipal Education Commission, Shanghai Education Development Foundation (grant no. 12CG19) and the Fundamental Research Funds for the Central Universities.

\section{References}

1. Cancer Genome Atlas Network: Comprehensive molecular portraits of human breast tumours. Nature 490: 61-70, 2012.

2. DeSantis C, Siegel R, Bandi P and Jemal A: Breast cancer statistics, 2011. CA Cancer J Clin 61: 409-418, 2011. 
3. de Bono JS, Tolcher AW and Rowinsky EK: The future of cytotoxic therapy: selective cytotoxicity based on biology is the key. Breast Cancer Res 5: 154-159, 2003.

4. Zafonte BT, Hulit J, Amanatullah DF, Albanese C, Wang C, Rosen E, Reutens A, Sparano JA, Lisanti MP and Pestell RG: Cell-cycle dysregulation in breast cancer: breast cancer therapies targeting the cell cycle. Front Biosci 5: D938-D961, 2000 .

5. Munagala R, Aqil F and Gupta RC: Promising molecular targeted therapies in breast cancer. Indian J Pharmacol 43 236-245, 2011.

6. Malumbres M and Barbacid M: Cell cycle, CDKs and cancer: a changing paradigm. Nat Rev Cancer 9: 153-166, 2009.

7. Schwartz GK and Shah MA: Targeting the cell cycle: a new approach to cancer therapy. J Clin Oncol 23: 9408-9421, 2005.

8. Chin YW, Balunas MJ, Chai HB and Kinghorn AD: Drug discovery from natural sources. AAPS J 8: E239-E253, 2006.

9. Rizk AM, Hammouda FM, El-Missiry MM, Radwan HM and Evans FJ: Biologically active diterpene esters from euphorbia peplus. Phytochemistry 24: 1605-1606, 1985.

10. Rasool N, Khan AQ and Malik A: A taraxerane type triterpene from Euphorbia tirucalli. Phytochemistry 28: 1193-1195, 1989.

11. de Melo JG, Santos AG, de Amorim EL, do Nascimento SC and de Albuquerque UP: Medicinal plants used as antitumor agents in Brazil: an ethnobotanical approach. Evid Based Complement Alternat Med 2011: 365359, 2011.

12. Akihisa T, Ogihara J, Kato J, Yasukawa K, Ukiya M, Yamanouchi S and Oishi K: Inhibitory effects of triterpenoids and sterols on human immunodeficiency virus-1 reverse transcriptase. Lipids 36: 507-512, 2001.

13. Akihisa T, Kithsiri Wijeratne EM, Tokuda H, Enjo F, Toriumi M, Kimura Y, Koike K, Nikaido T, Tezuka Y and Nishino $\mathrm{H}$ Eupha-7,9(11), 24-trien-3beta-ol ('antiquol C') and other triterpenes from Euphorbia antiquorum latex and their inhibitory effects on Epstein-Barr virus activation. J Nat Prod 65: 158-162, 2002.

14. Dutra RC, Claudino RF, Bento AF, Marcon R, Schmidt EC, Bouzon ZL, Pianowski LF and Calixto JB: Preventive and therapeutic euphol treatment attenuates experimental colitis in mice. PLoS One 6: e27122, 2011

15. Dutra RC, de Souza PR, Bento AF, Marcon R, Bicca MA, Pianowski LF and Calixto JB: Euphol prevents experimental autoimmune encephalomyelitis in mice: evidence for the underlying mechanisms. Biochem Pharmacol 83: 531-542, 2012.

16. Passos GF, Medeiros R, Marcon R, Nascimento AF, Calixto JB and Pianowski LF: The role of PKC/ERK1/2 signaling in the anti-inflammatory effect of tetracyclic triterpene euphol on TPA-induced skin inflammation in mice. Eur J Pharmacol 698 413-420, 2012.

17. Yasukawa $\mathrm{K}$, Akihisa $\mathrm{T}$, Yoshida $\mathrm{ZY}$ and Takido $\mathrm{M}$ Inhibitory effect of euphol, a triterpene alcohol from the roots of Euphorbia kansui, on tumour promotion by 12-O-tetradecanoylphorbol-13-acetate in two-stage carcinogenesis in mouse skin. J Pharm Pharmacol 52: 119-124, 2000.
18. Livak KJ and Schmittgen TD: Analysis of relative gene expression data using real-time quantitative PCR and the 2(-Delta Delta C(T)) Method. Methods 25: 402-408, 2001.

19. O'Connor PM, Jackman J, Bae I, Myers TG, Fan S, Mutoh M, Scudiero DA, Monks A, Sausville EA, Weinstein JN, et al: Characterization of the p53 tumor suppressor pathway in cell lines of the National Cancer Institute anticancer drug screen and correlations with the growth-inhibitory potency of 123 anticancer agents. Cancer Res 57: 4285-4300, 1997.

20. Gillett C, Fantl V, Smith R, Fisher C, Bartek J, Dickson C, Barnes D and Peters G: Amplification and overexpression of cyclin D1 in breast cancer detected by immunohistochemical staining. Cancer Res 54: 1812-1817, 1994.

21. Zukerberg LR, Yang WI, Gadd M, Thor AD, Koerner FC, Schmidt EV and Arnold A: Cyclin D1 (PRAD1) protein expression in breast cancer: approximately one-third of infiltrating mammary carcinomas show overexpression of the cyclin D1 oncogene. Mod Pathol 8: 560-567, 1995.

22. Lin SY, Xia W, Wang JC, Kwong KY, Spohn B, Wen Y, Pestell RG and Hung MC: Beta-catenin, a novel prognostic marker for breast cancer: its roles in cyclin D1 expression and cancer progression. Proc Natl Acad Sci USA 97: 4262-4266, 2000.

23. Vermeulen K, Van Bockstaele DR and Berneman ZN: The cell cycle: a review of regulation, deregulation and therapeutic targets in cancer. Cell Prolif 36: 131-149, 2003.

24. Pagano M, Tam SW, Theodoras AM, Beer-Romero P, Del Sal G, Chau V, Yew PR, Draetta GF and Rolfe M: Role of the ubiquitin-proteasome pathway in regulating abundance of the cyclin-dependent kinase inhibitor p27. Science 269: 682-685, 1995.

25. Nigro JM, Baker SJ, Preisinger AC, Jessup JM, Hostetter R, Cleary K, Bigner SH, Davidson N, Baylin S, Devilee P, et al: Mutations in the p53 gene occur in diverse human tumour types. Nature 342: 705-708, 1989.

26. Girard F, Strausfeld U, Fernandez A and Lamb NJ: Cyclin A is required for the onset of DNA replication in mammalian fibroblasts. Cell 67: 1169-1179, 1991.

27. Resnitzky D, Hengst L and Reed SI: Cyclin A-associated kinase activity is rate limiting for entrance into $\mathrm{S}$ phase and is negatively regulated in G1 by p27Kip1. Mol Cell Biol 15: 4347-4352, 1995.

28. Knoblich JA and Lehner CF: Synergistic action of Drosophila cyclins $A$ and $B$ during the G2-M transition. EMBO J 12: 65-74, 1993.

29. Li H, Sun L, Tang Z, Fu L, Xu Y, Li Z, Luo W, Qiu X and Wang E: Overexpression of TRIM24 correlates with tumor progression in non-small cell lung cancer. PLoS One 7: e37657, 2012.

30. Darzynkiewicz Z, Bruno S, Del Bino G, Gorczyca W, Hotz MA Lassota P and Traganos F: Features of apoptotic cells measured by flow cy tometry. Cytometry 13: 795-808, 1992.

31. Nieves-Neira W and Pommier Y: Apoptotic response to camptothecin and 7-hydroxystaurosporine (UCN-01) in the 8 human breast cancer cell lines of the NCI Anticancer Drug Screen: multifactorial relationships with topoisomerase I, protein kinase $\mathrm{C}, \mathrm{Bcl}-2$, p53, MDM-2 and caspase pathways. Int J Cancer 82: 396-404, 1999. 